\title{
Feasibility Research of SS304 Serving as the Positive Current Collector of Li||Sb-Sn Liquid Metal Battery
}

Kaixuan Cuit, Fuqiang Ant*, Wang Zhao, Ping Li**, Shengwei Li, Chunrong Liu, Xuanhui Qu

Beijing Advanced Innovation Center for Materials Genome Engineering, Institute for Advanced Materials and Technology, University of Science and Technology Beijing, Beijing, 10083, China

* Corresponding author

**Corresponding author

E-mail addresses: 151388157@qq.com (F. An), ustbliping@126.com (P. Li)

f These authors contributed equally to this work. 
Table S1. Compositions of SS304 (in wt\%)

\begin{tabular}{ccccccccc}
\hline & $\mathrm{Fe}$ & $\mathrm{Cr}$ & $\mathrm{Ni}$ & $\mathrm{C}$ & $\mathrm{Mn}$ & $\mathrm{P}$ & $\mathrm{S}$ & $\mathrm{Si}$ \\
\hline $\mathrm{SS} 304$ & 71.89 & 18.55 & 8.09 & 0.084 & 0.89 & 0.018 & 0.0083 & 0.46 \\
\hline
\end{tabular}

Table S2. Elements atomic percent at different positions of cross-sectional SEM images about static corrosion (Fig. 2)

\begin{tabular}{|c|c|c|c|c|c|c|c|c|}
\hline Sample & Position & $\mathrm{Fe}$ & $\mathrm{Cr}$ & $\mathrm{Ni}$ & $\mathrm{Sb}$ & $\mathrm{Sn}$ & $\mathrm{O}$ & Total \\
\hline \multirow{3}{*}{$\mathrm{Fe}$} & 1 & 39.09 & 0.00 & 0.00 & 25.40 & 27.97 & 7.54 & 100.00 \\
\hline & 2 & 48.83 & 0.00 & 0.00 & 26.20 & 18.01 & 6.96 & 100.00 \\
\hline & 3 & 45.19 & 0.00 & 0.00 & 26.97 & 20.38 & 7.46 & 100.00 \\
\hline \multirow{3}{*}{$\mathrm{Cr}$} & 4 & 0.00 & 1.06 & 0.00 & 38.30 & 47.14 & 13.50 & 100.00 \\
\hline & 5 & 0.00 & 41.70 & 0.00 & 43.79 & 5.32 & 9.19 & 100.00 \\
\hline & 6 & 0.00 & 9.24 & 0.00 & 35.79 & 43.61 & 11.36 & 100.00 \\
\hline \multirow{3}{*}{$\mathrm{Ni}$} & 7 & 0.00 & 0.00 & 0.35 & 43.09 & 50.51 & 6.05 & 100.00 \\
\hline & 8 & 0.00 & 0.00 & 46.21 & 31.73 & 18.71 & 3.35 & 100.00 \\
\hline & 9 & 0.00 & 0.00 & 66.64 & 16.78 & 12.10 & 4.48 & 100.00 \\
\hline \multirow{3}{*}{ SS304 } & 10 & 0.20 & 0.17 & 0.28 & 39.19 & 50.30 & 9.87 & 100.00 \\
\hline & 11 & 23.64 & 1.78 & 4.87 & 57.29 & 6.29 & 6.13 & 100.00 \\
\hline & 12 & 44.46 & 6.25 & 0.84 & 31.97 & 9.84 & 6.64 & 100.00 \\
\hline
\end{tabular}




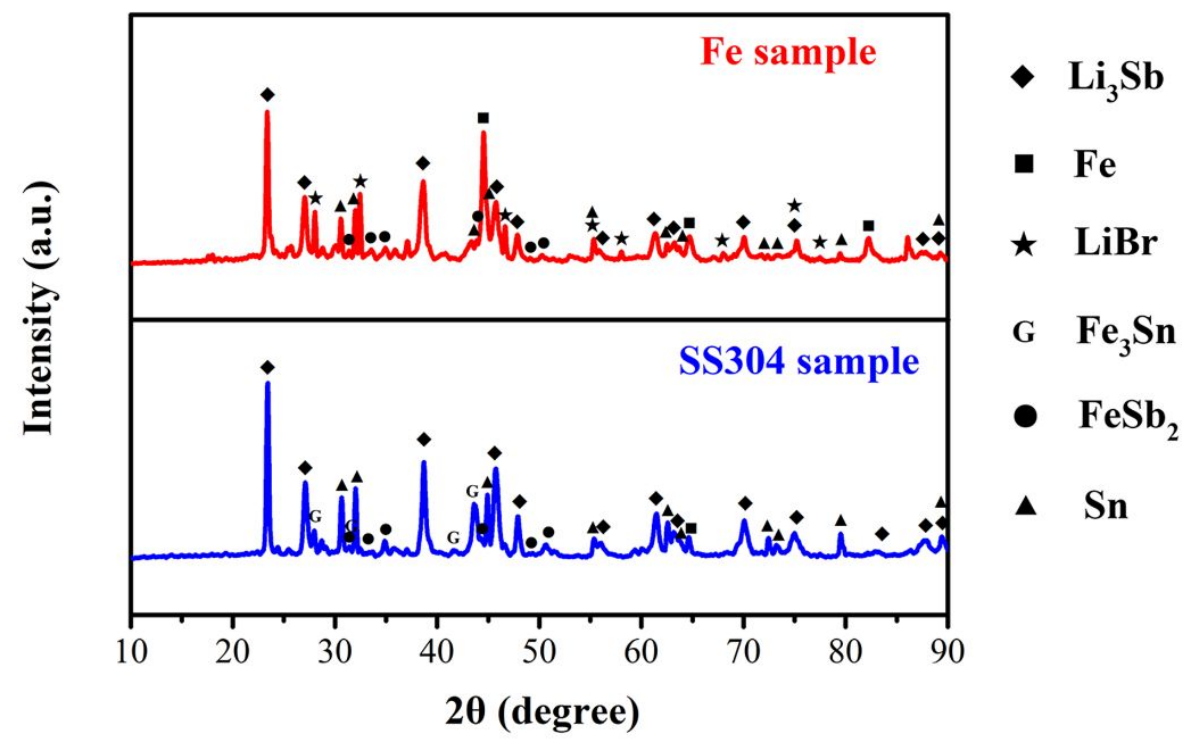

Figure S1. XRD patterns of discharging products after static corrosion of Fe and SS304 in Sb-Sn alloy. 


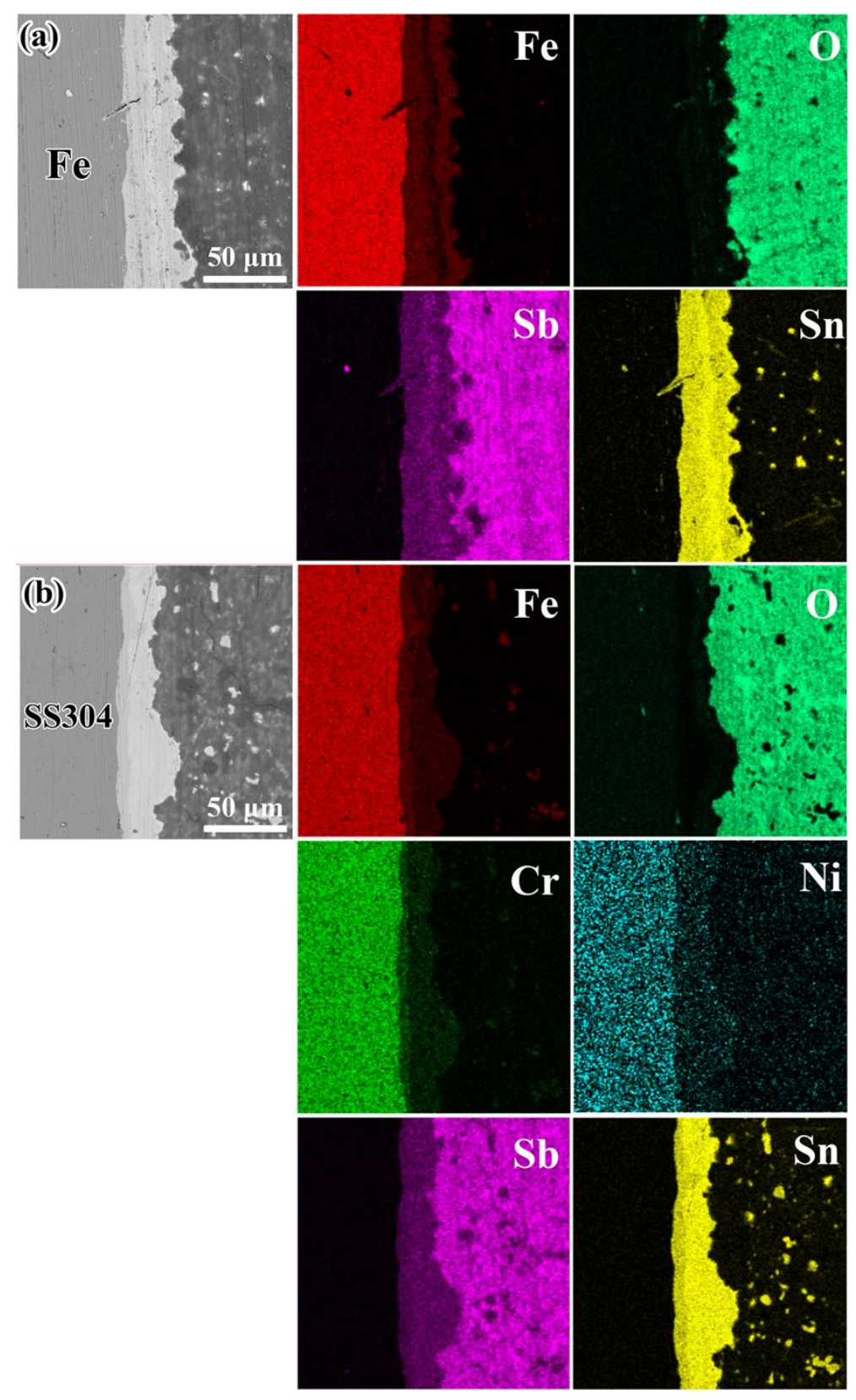

Figure S2. (a) Cross-sectional SEM and EDS element mapping images about static corrosion of Fe in Li-Sb-Sn alloy. (b) Cross-sectional SEM and EDS element mapping images about static corrosion of SS304 in Li-Sb-Sn alloy. The operating temperature and time were $500^{\circ} \mathrm{C}$ and $168 \mathrm{~h}$, respectively. 

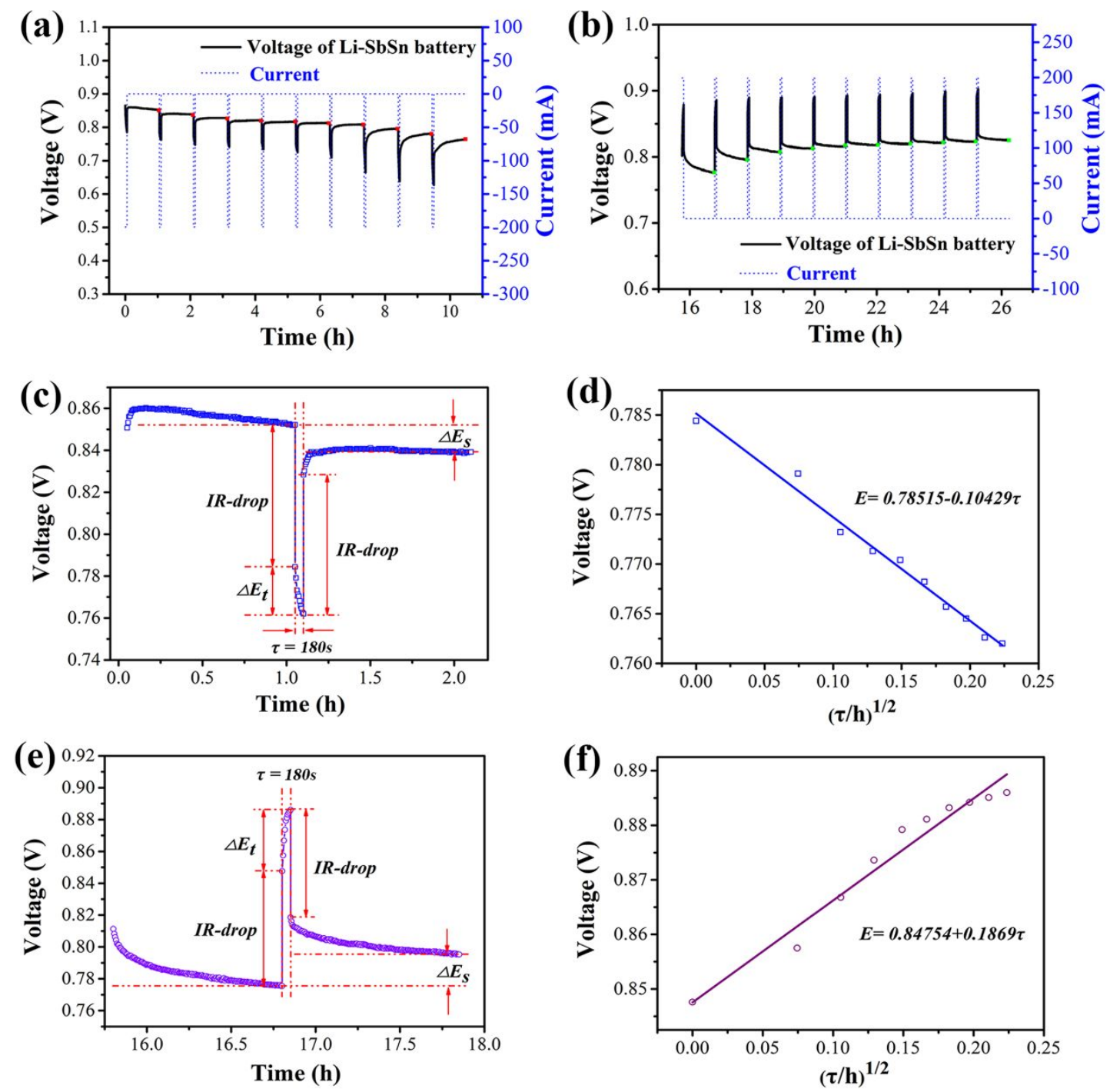

Figure S3. The first 10 (a) lithiation and (b) delithiation processes of the Coulometric titration of Li ||Sb-Sn liquid metal battery. (c) Scheme for a single step of the Coulometric titration at around $0.84 \mathrm{~V}$ during the first discharge process of $\mathrm{Li}|| \mathrm{Sb}$-Sn liquid metal battery: $\tau$ (constant current pulse time), $\Delta \mathrm{E}_{\mathrm{t}}$ (a total change of cell voltage during constant current pulse neglecting the IR-drop) and $\Delta \mathrm{E}_{\mathrm{s}}$ (change of the steady-state voltage). (d) Variation of cell voltage for the above titration plotted against $\tau^{1 / 2}$ to show the linear fit. (e) Scheme for a single step of the Coulometric titration at around $0.79 \mathrm{~V}$ during the first charge process of Li||Sb-Sn liquid metal battery. (f) Variation of cell voltage for the above titration plotted against $\tau^{1 / 2}$ to show the linear fit.

Fig. S3d and f respectively show a straight line behavior on the variation of cell 
voltage $E$ during lithiation and delithiation processes of titration vs $\tau^{1 / 2}$, and the $\mathrm{Li}^{+}$ diffusion coefficient can be calculated with the following formula $[1,2]$ :

$$
D_{L i^{+}}=\frac{4}{\pi \tau}\left(\frac{n_{m} V_{m}}{S}\right)^{2}\left(\frac{\Delta E_{s}}{\Delta E_{t}}\right)^{2}
$$

Where $\tau$ is the duration of the current pulse (s); $n_{m}$ is the number of moles (mol); $V_{m}$ is the molar volume of the electrode $\left(\mathrm{cm}^{3} / \mathrm{mol}\right) ; S$ is the electrode/electrolyte contact area $\left(\mathrm{cm}^{2}\right) ; \Delta E_{s}$ is the steady state voltage change, and $\Delta E_{t}$ is the transient state voltage change, they are shown in Fig. S3(c) and (e), respectively. The $\tau, S, \Delta E_{S}$ and $\Delta E_{t}$ can be acquired by experimental details while the $n_{m}$ and $V_{m}$ can be calculated according to the relevant literature. [3]

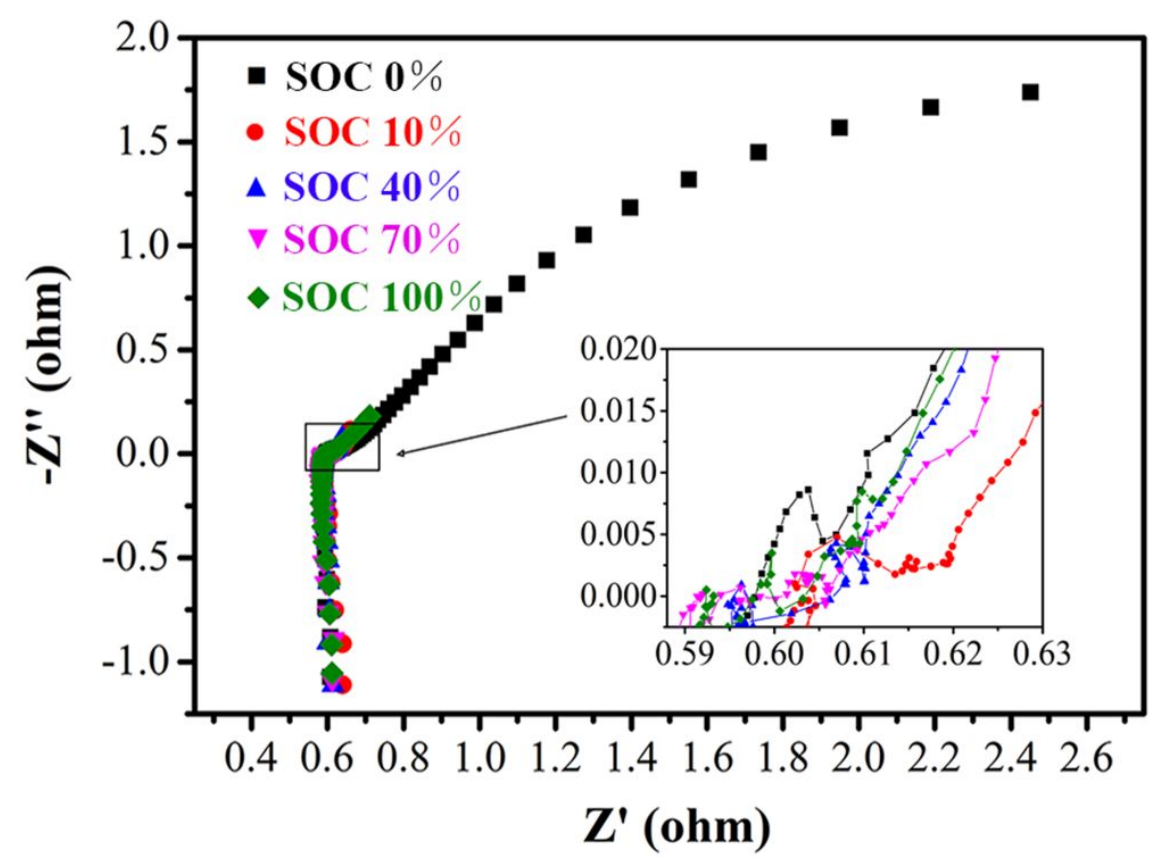

Figure S4. Nyquist plots at different SOC $(0 \%, 10 \%, 40 \%, 70 \%, 100 \%)$. The operating temperature was $500^{\circ} \mathrm{C}$. 

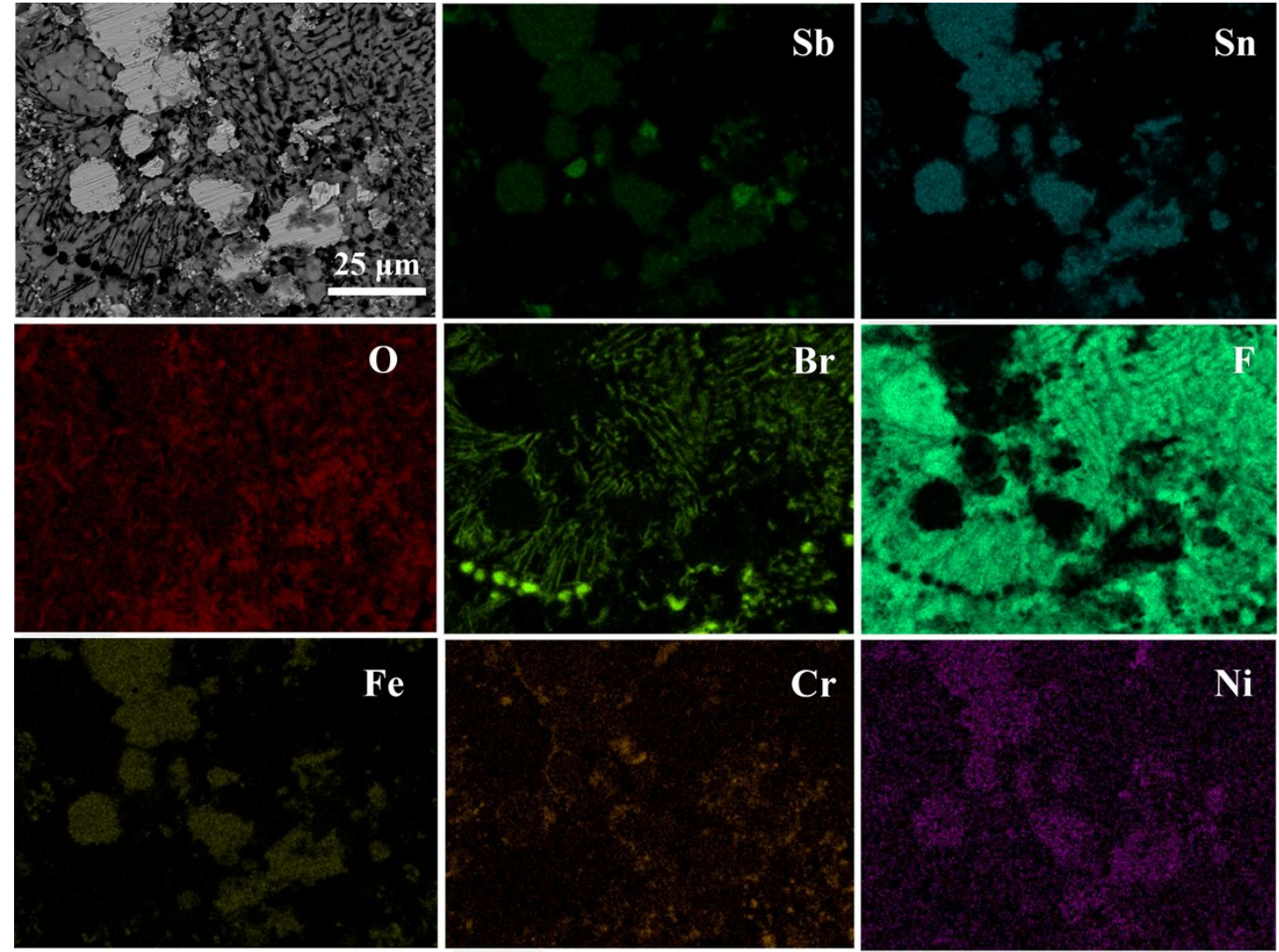

Figure S5. Cross-sectional SEM and EDS element mapping images of $\mathrm{Sb}_{40} \mathrm{Sn}_{60}$ positive electrode and SS304 positive current collector. This cell was cycled 100 times and stopped at a fully charged state.

\section{References}

(1) Shen, Z.; Cao, L.; Rahn, C. D.; Wang, C.-Y. Least squares galvanostatic intermittent titration technique (ls-gitt) for accurate solid phase diffusivity measurement. J. Electrochem. Soc. 2013, 160, A1842-A1846.

(2) Rui, X.; Yesibolati, N.; Li, S.; Yuan; C.; Chen, C. Determination of the chemical diffusion coefficient of $\mathrm{Li}+$ in intercalation-type $\mathrm{Li}_{3} \mathrm{~V}_{2}\left(\mathrm{PO}_{4}\right)_{3}$ anode material. Solid State Ionics 2011, 187, $58-63$. 
(3) Gasior, W.; Moser, Z.; Pstruś, J. Surface tension, density, and molar volume of liquid Sb-Sn alloys: Experiment versus modeling. J. Phase Equilib. 2003, 24, 504-510. 